\title{
ENFOQUE HUMANÍSTICO À COMUNICAÇÃO EM ENFERMAGEM: O CASO DE UMAADOLESCENTE HOSPITALIZADA
}

\author{
HUMANISTIC APPROACH TO NURSING COMMUNICATION: THE CASE OF \\ A HOSPITALIZED FEMALE ADOLESCENT \\ ENFOQUE HUMANISTICO DE LA COMUNICACIÓN EN ENFERMERIAA : EL \\ CASO DE UNAADOLESCENTE HOSPITALIZADA
}

\author{
Isabel Amélia Costa Mendes ${ }^{1}$ \\ Maria Auxiliadora Trevizan' \\ Maria Suely Nogueira ${ }^{2}$ \\ Miyeko Hayashida ${ }^{3}$
}

\begin{abstract}
RESUMO: A enfermagem é uma profissão que milita pela promoção do ser humano, com toda sua liberdade, unicidade e dignidade. Neste sentido, a comunicação reveste-se de um significado essencial tanto no transcorrer do processo de enfermagem, quanto no seu produto, constituindo-se também como um componente fundamental do tratamento. Entretanto, no contexto hospitalar brasileiro, a comunicação do enfermeiro com o paciente tem sido limitada ao cumprimento de seu papel instrumental. A proposta deste estudo é analisar o caso de uma adolescente hospitalizada, enfocando sua comunicaçăo com os enfermeiros que Ihes dispensaram cuidados. Esta análise alicerçou-se no paradigma categorial de Bales. Através da técnica de observação direta do comportamento resultante da interação entre os enfermeiros e a adolescente estudada, durante trinta horas distribuidas em cinco dias, foram computadas 428 unidades de interação, as quais foram classificadas em áreas sócio-emocional positiva, negativa e neutra por juizes habilitados para esta atividade. Dado o alto indice de interações na área neutra $(89,3 \%)$, as autoras recomendam uma correção humanistica na comunicação durante o processo de enfermagem, o que poderá contribuir para qualificar o cuidado e redundar em satisfação no trabalho através do exercicio da empatia e da solidariedade.
\end{abstract}

PALAVRAS-CHAVE: comunicação, humanização, enfermagem, hospital, interação

\section{INTRODUÇÃO}

A enfermagem tem sido caracterizada como uma profissão que milita pela promoção do ser humano, com toda a sua liberdade, unicidade e dignidade. É uma profissão sensivel à adoção de valores que, aliados aos conhecimentos específicos, sustentam e norteiam o exercício das competências que têm como finalidade promover saúde, prevenir doença e cuidar de enfermos. E para cuidar não é suficiente saber; o cuidar implica de igual modo a necessidade de um conjunto de atitudes que permitam a aplicação melhor e integral do saber adquirido.

Em decorrência deste traço da profissão, o preparo do enfermeiro deve abarcar um

\footnotetext{
1 Enfermeira, Mestre, Doutora, Livre-Docente. Prof. Titular EERP - USP.

2 Enfermeira, Mestre, Doutora em Enfermagem. Professora EESP-USP. EERP-USP

3 Enfermeira, Mestre, Doutora em Enfermagem. Chefe da Seçăo de Apoio Laboratorial da
} 
componente humanístico no processo de formação. Além disso, considerando que hoje vivemos a era do conhecimento, com intensas transformações sociais, o humanismo deve integrar o substrato cultural do enfermeiro não apenas no seu processo de formação, mas em todo o processo de educação continuada.

Em suma, o humanismo é um valor que a enfermagem conserva como filosofia na formação e sobretudo como imperioso ingrediente na busca de equilibrio entre a vertente da técnica e o comportamento humanitário do enfermeiro, especialmente na sociedade contemporânea contornada por fortes traços de elevada tecnologia e de pouco contato humano.

A valorização do homem como pessoa é uma pré-condição para a humanização no contexto da enfermagem. Segundo Correia (1996), o fundamento preliminar da alteridade é a pessoa, vista enquanto abertura, relação e comunicabilidade. Afirma ele: "pelo fato de uma pessoa ser abertura ou intersubjetividade é que podemos afirmar ser ela também alteridade". Deste modo, alteridade é entendida pelo autor como integrante essencial do conceito de pessoa, o que o leva a tratar a relação médico-paciente como relação de alteridade. Acrescentariamos, conforme nos induz o autor, que a alteridade constitui o critério fundamental e englobante também do relacionamento enfermeiro-paciente, na medida em que este for caracterizado como um encontro de pessoas e que assim se consideram.

Sob esta ótica, a comunicação desempenha papel preponderante para práxis da alteridade na relação enfermeiro-paciente. A comunicação é um veículo através do qual a humanização pode ser praticada e também investigada (Mendes, 1994). Sim, porque sendo um valor conceitualmente incorporado, há que se verificar na prática se existe correspondência. Conforme aponta Carvalho (1996), a enfermagem encontra-se envolvida em crise do humanismo. Pretendendo contribuir com o debate desta questão, selecionaremos a comunicação como uma das variáveis passíveis de investigar a humanização do cuidado de enfermagem. Reduzindo o universo de sujeitos de pesquisa, a proposta deste estudo é analisar o caso de uma adolescente hospitalizada, enfocando sua comunicação com as enfermeiras e com o grupo de enfermagem que the dispensou cuidados.

\section{METODOLOGIA}

Os dados empiricos nos quais nos debruçamos neste estudo originaram-se de pesquisa conduzida em hospital universitário brasileiro. Na abordagem preliminar todos os pacientes foram orientados acerca do propósito do estudo, esclarecidos sobre as técnicas que seriam utilizadas garantido-Ihes direito de recusa à participação, assim como de anonimato, caso concordassem em participar. Após a obtenção de concordância e do consentimento declarado da paciente selecionada para o estudo, deu-se por iniciado o processo de coleta de dados. Uma paciente adolescente foi observada desde o momento da internação até a alta hospitalar, durante sua permanência na clinica por quatro dias consecutivos, das sete as onze e das treze às dezenove horas. A observação direta de seu comportamento verbal e não verbal foi registrada por observadores treinados usando a técnica de registro com lápis e papel. Os dados oriundos deste registro foram classificados à luz da teoria e do sistema de categorias de interação de Robert Bales (1970). Tal sistema é composto por doze categorias divididas em três áreas de reação: positiva, neutra e negativa.

\section{RESULTADOS E DISCUSSÃO}

A paciente sob investigação será aqui identificada como Maria, possui 18 anos, é solteira, com escolaridade básica, residente no meio urbano, tendo a primeira experiência de hospitalização para tratamento numa enfermaria de oito leitos na unidade de interação ginecológica. O diagnóstico médico registrado no prontuário foi "fibroadenoma hipercelular" e a 
finalidade de internação foi submetê-la a "exerese de fibroma gigante de mama esquerda".

Após 30 horas de observação e do registro de comportamento verbal foram extraídas 428 unidades de interaçăo trocadas entre Maria e o grupo da enfermagem que Ihe prestou cuidados. Os dados contidos na figura 1 dão visibilidade do padrão de interação, indicando uma preponderância da área neutra $(89,3 \%)$ sobre as demais: positiva $(4,0 \%)$ e negativa $(6,7 \%)$.

Fig. 1. Percentual de interações apresentadas pela paciente em cada Categoria de Bales

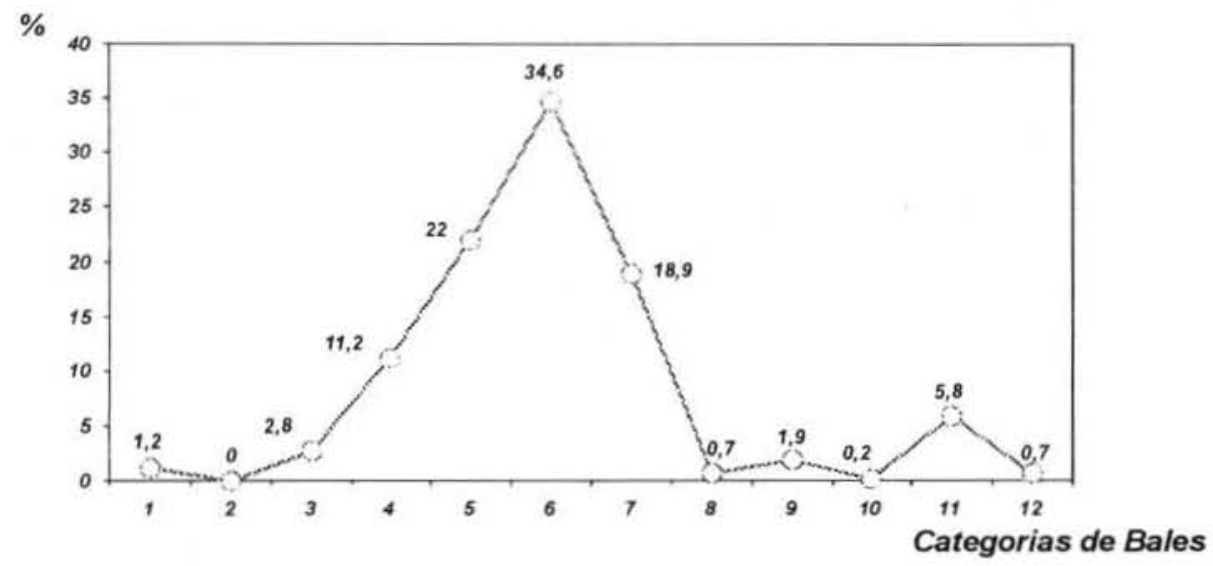

Área Positiva (1, 2 e 3), Área Neutra (4, 5, 6, 7, 8 e 9), Área Negativa (10, 11 e 12)

Para oferecer uma visão mais globalizante das circunstâncias nas quais estava inserida a paciente, apresentamos em seguida uma sintese de sua internação contendo alguns dos principais diálogos mantidos com ela.

\section{SINTESE DAS INTERAÇÖES E SEU CONTEXTO}

Acompanhada de sua mãe, Maria compareceu no setor de controle de leitos atendendo solicitação médica. Antes de ser encaminhada à rotina de internação, foi examinada por especialista no ambulatório, o qual confirmou o seu pedido de internação. Ao sair da sala de exames pareceu estar impaciente, aflita e com sinais de que havia chorado. Durante o cumprimento de todas as etapas rotineiras da internação mostrou-se extremamente nervosa, irritada e apreensiva. Reclamou para a mãe da fome que estava sentindo e da demora do processo de sua internação, que teve duração de cinco horas. Ao chegar finalmente na clínica foi recebida pela auxiliar às 16:45 horas; esta mostrou o seu quarto, sua unidade, as companheiras de quarto e perguntou se já havia sido internada antes. Obtendo resposta negativa, a auxiliar perguntou: - Está tudo bem com você? Está com fome? A paciente respondeu: - Tudo bem, estou com um pouquinho de fome sim. Diante desta reposta, sua mãe interferiu dizendo: Pudera! Só tomou o café da manhã até agora... A auxiliar respondeu: Bem, agora já está quase na hora da janta, né? Fique a vontade que daqui a pouco venho medir sua pressão, tá? Depois de sua mãe ter se despedido, a auxiliar verificou os sinais vitais e perguntou se a paciente estava se sentindo bem, obtendo a seguinte resposta: - Estou só com um pouquinho de medo. A auxiliar permaneceu mais alguns instantes ao lado da paciente enquanto fazia anotações no prontuário e depois retirou-se dizendo: Agora mesmo vem a janta, viu Maria? Você deve estar com fome, né?

No outro dia ainda estava muito timida e apreensiva. Depois que duas atendentes verificaram seus sinais vitais sem dirigirem-Ihe a palavra, uma delas retornou à enfermaria e disse: - Quem 
falta tomar banho? Maria respondeu baixo Eu. A atendente inquiriu: Eu quem? Ela balbuciou: Aqui. A atendente ordenou: Então vai! Você tem toalha? Tendo respondido que não, a atendente ofereceu-lhe uma toalha e ela então dirigiu-se ao banheiro. No horário do café uma paciente convidou-a para vir ao refeitório e com ela conversou, mencionando que percebeu que não havia dormido nada durante à noite, pois todas as vezes que acordava verificava que Maria estava acordada. A paciente observada concordou timidamente com as observações da colega, sem nada acrescentar. Logo após, a paciente estava já na enfermaria, sentada à mesa e com expressão triste, quando surge um médico na porta da enfermaria e se dirige à aluna de enfermagem, que lá estava a conversar com outra paciente, perguntando-lhe: Está nesta enfermaria uma paciente jovem que foi internada ontem e tem um tumor grande de mama? A própria paciente respondeu: Sou eu. O médico perguntou-lhe: Então é você que vai ser operada amanhã? Vamos deixar você linda, vai ver. A paciente, assustada, perguntou: Vocês não vão tirar o meu seio, né? Ele disse: Não, imagine! Uma carinha tão bonita... Vamos deixar você linda; pode dormir tranqüila, tá? retirando-se da enfermaria. A paciente permanece sentada, mordendo os lábios superiores. Nisto uma aluna de enfermagem aproxima-se dela perguntando: Você está bem? e ela respondeu: Estou mais ou menos. A aluna pergunta qual o leito dela, mas foi interrompida por outra paciente que a chamou. Como a aluna foi atender à outra, Maria desabafou-se com a paciente mais próxima a ela: Estou morrendo de medo, dona Anita. Esta afirmou: - Estou vendo! Você está apavorada. Não pode ficar assim não! Tem que ter fé e sempre pensar o melhor. Em seguida entrou um grupo de médicos que se dirigiu a uma outra paciente. Maria prestou muita atenção no que diziam; permaneceu sentada ainda aparentando preocupação, quando, uma aluna de enfermagem a abordou:

aluna: - E você Maria ? Dormiu Bem?

paciente: - Dormi.

aluna: - Está tudo bem? Não estranhou a cama?

paciente: - Tudo bem. Não estranhei não.

aluna: - É a primeira vez que você interna?

paciente: - $\dot{E}$.

aluna: - O médico já veio te falar alguma coisa, ou te examinar? Durante esta pergunta a aluna folheava o prontuário.

paciente: - Não, ainda não.

aluna: - Mais tarde o médico vem te ver, te examinar e se tiver tudo bem vai para a cirurgia amanhã, viu? Agora me conta: o que aconteceu mesmo esta noite? Você ficou nervosa?

paciente: - Fiquei sim.

aluna: - É compreensivel, né? E você está nervosa até agora, né?

paciente: - Um pouquinho, disse quase chorando.

aluna: A gente vai conversar melhor mais tarde, viu? O que você tomou de manhã? Leite e pão? paciente: Foi.

aluna: - Está evacuando e urinando direitinho? Não prendeu?

paciente: Estou. Não prendeu nada não.

A aluna fez anotações no prontuário e se afastou indo conversar com outra paciente. A paciente observada começou a ler uma revista e foi chamada para um exame, no qual o médico confirmou a cirurgia para a manhã seguinte. Depois de realizado o preparo para a cirurgia (tricotomia e coleta de sangue para contra-prova) por outra aluna de enfermagem, a paciente apresentava uma expressão pouco mais calma, embora se mantivesse pensativa. À tarde trocou algumas frases com uma colega e ouviu a conversa de duas outras, emitindo alguns sorrisos quando achava graça do que falavam. A paciente estava já um pouco mais à vontade quando um médico e uma enfermeira entraram, tendo ele dito: Arruma aquela paciente ali prá mim; eu quero fotografá-la, apontando para Maria. A paciente mostrou desagrado, que foi ignorado tanto pelo médico, como pela enfermeira. O médico chamou-a novamente e a paciente o acompanhou 
até a sala de curativos, onde recebeu o seguinte pedido: Sente-se aqui de costas para este biombo, assim. Desabotoe a camisola e tire, por favor. Ajeitou o equipamento fotográfico e bateu algumas fotos em várias posições, sendo que a paciente, demonstrando tensão, obedecia aos comandos do médico para mudança de posição. Quando ele terminou, disse: Pronto, pode se vestir, retirando-se da sala. A paciente retirou-se também, indo para o quarto.

No dia da cirurgia, quando voltou da recuperação, queixou-se um pouco de dor e passou a tarde dormindo.

Na manhã seguinte já aparentava estar mais adaptada ao ambiente, conversando com as pacientes e dirigindo-se ao refeitório. Queixou-se de não ter dormido porque o medicamento fez mal e porque o colchão é ruim. Referiu vontade de ir embora e ficou a observar ora o movimento da enfermaria, ora o movimento do pátio do hospital através da janela. Mencionou para uma paciente que ficou muito assustada com sua doença, tendo a outra tranqüilizado Maria. Na visita médica foi informada de que já receberia alta e perguntou ao cirurgião sobre 0 que tinha sido feito em sua mama e se o problema ia voltar. O médico explicou, deixando-a tranqüila e despediu-se informando que a encontrará no ambulatório. A paciente ficou bastante animada com a noticia, contou para as colegas com muita alegria e chegou até a cantarolar. Por outro lado, em alguns momentos pareceu insegura quanto à alta porque referia dores no corpo e medo de sentir-se mal em casa. À tarde queixou-se de dor para o médico que a tranqüilizou, orientando-a para comparecer no ambulatório na próxima semana para avaliação e retirada dos pontos. Saiu de a ta ao final da tarde.

Vinte e oito pessoas tiveram contato com Maria durante o período observado, sendo dezesseis do Serviço de Enfermagem: - quatro auxiliares, um técnico, três enfermeiras, cinco atendentes e três alunas de enfermagem, afora os pacientes. O perfil da interação entre estes atores configura um padrão centrado na área neutra, ou de tarefas, conforme preconizado por Bales; portanto, o repertório verbal é determinado por questões funcionais e de interesse do grupo que presta cuidados. E, pela sintese aqui exposta, é possivel identificar que o grupo esquiva-se de interações que se enveredam para as áreas sócio-emocionais, sejam elas positivas ou negativas. A paciente adolescente, com um problema físico totalmente desconhecido para ela, apresentando necessidade de orientação e informação em grau máximo, não obtém antes da cirurgia o que ela mais anseia, nem do grupo de enfermagem nem do grupo médico. Tanto que após a cirurgia quando já ia receber alta, ela ainda pergunta ao médico sobre o que tinha sido feito em sua mama e se o problema estaria ou não resolvido.

Durante sua internação, no nosso entender, o conjunto de interações ou melhor de comandos que a paciente recebeu, mais dramático ocorreu no momento da documentação fotográfica pré-cirúrgica. Não tendo o médico explicado o motivo do procedimento, caberia a enfermeira fazê-lo, mesmo que fosse diante do médico, falando por ele. Ela teria que demonstrar através de comunicação verbal e não verbal que estaria conectada com a paciente, compartilhando com ela uma experiência que não seria violenta se fosse precedida e acompanhada de orientação. Estaria a enfermeira, neste caso, exercendo moralmente a enfermagem, o que, segundo Meleis (1997) seria a arte que inclui a visão de quais habilidades são importantes, mas não substitutas de outros aspectos da prática e nem suficientes para atendimento das necessidades dos pacientes. Afirma a autora: "se uma enfermeira não faz escolhas morais ou enfrenta dilemas morais em sua prática, então ela não está usando aspectos artísticos da disciplina".

A paciente estudada não foi acolhida pelo grupo de enfermagem como seria de se esperar.

Segundo Marcel (1947), receber o outro seria, antes de mais nada, estabelecer um ambiente de acolhida, impregnando-o de uma certa familiaridade. Neste sentido e no caso da enfermagem, em primeiro lugar fazer com que o outro perceba que está diante de um determinado enfermeiro, e não diante de um enfermeiro qualquer. Decorrência direta desta postura será o estabelecimento de uma relação familiar entre os que se encontram. 
Durante o periodo de internação da paciente que constitui o foco deste trabalho, foi possivel identificar vários exemplos de falta de acolhida e de desrespeito à necessidade de informação e de segurança, especialmente por sua condição de adolescente feminina, em primeira internação causada por um "tumor" em uma das mamas, instalada em um ambiente onde profissionais a tratam orientados apenas por suas próprias funções, sem oferecer informações sobre o tratamento e procedimento para fazê-la participar do processo e reduzir seu nivel de tensão, acentuado pelo medo do desconhecido. Isto é, não se colocam no seu lugar.

Os resultados do presente estudo apontam para a necessidade de assunção de responsabilidade compartilhada entre os enfermeiros (tanto da área ensino, como da área assistencial) no sentido de buscarem continuamente o resgate do valor da arte da enfermagem entendida em sua configuração mais plena, de modo que a humanização seja prestigiada e demonstrada através das competências em comunicação como uma das maneiras para o alcance de maior eficiência e de melhor qualidade do cuidado prestado, redundando em satisfação no trabalho através do exercício da empatia e da solidariedade.

\begin{abstract}
Nursing is a profession committed to the promotion of human beings. It takes into consideration their freedom, uniqueness and dignity. Therefore, communication plays an important role within the nursing process and its results, and it is also a fundamental component of the treatment. However, in the context of Brazilian hospitals, communication between nurses and patients is limited to the performance of these professionals' technical role. The purpose of this study is to analyse the case of a hospitalized female adolescent, focusing on the communication that happens between her and the nursing professionals who provide her assistance. This analysis was based on Bales' categories. Through the technique of direct observation, the behavior resultant from the interaction between nurses and the adolescent was analysed on a total of 30 hours during five days. The observation showed 428 units of interaction which were classified, by qualified professionals, in positive, negative and neutral socio-emotional areas. Considering the high incidence of interactions in the neutral area $(89,2 \%)$, authors recommend a humanistic correction in the communication during the nursing process. This change in communication can qualify patient's care as well as generate satisfaction at work through empathy and solidarity.
\end{abstract}

KEYWORDS: communication, humanization, nursing, hospital, interaction

\begin{abstract}
RESUMEN: La enfermeria es una profesión que lucha por la promoción del ser humano con toda su libertad, unicidad y dignidad. En ese sentido, la comunicación se reviste de un significado esencial tanto en el transcurrir del proceso de enfermeria, como en su producto, constituyéndose también como un componente fundamental del tratamiento. Sin embargo, en el contexto hospitalario brasileño, la comunicación del enfermero con el paciente se ha limitado al cumplimiento de su papel instrumental. La propuesta de este estudio es analizar el caso de una adolescente hospitalizada enfocando su comunicación con los enfermeros que la cuidaron. El análisis se basa en el paradigma categorial de Bales. Mediante la técnica de la observación directa del comportamiento resultante de la interacción entre los enfermeros y la adolescente estudiada, durante treinta horas distribuidas en cinco dias, se computaron 428 unidades de interacción, las cuales se clasificaron en áreas socioemocionales positiva, negativa y neutra por jueces habilitados para tal actividad. Como el indice de interacciones en el área neutra $(83,9 \%)$, se presentó muy elevado, las autoras recomiendan una corrección humanistica en la comunicación durante el proceso de enfermeria, lo que podrá contribuir para calificar el cuidado y resultará en mayor satisfacción en el trabajo, debido al ejercicio de la empatia y de la solidaridad.
\end{abstract}

PALABRAS CLAVE: comunicación, humanización, enfermeria, hospital, interacción 


\section{REFERÊNCIAS BIBLIOGRÁFICAS}

BALES, R.F. Personality and interpersonal behavior. New York: Holt, Rinehart and Winston, 1970.

CARVALHO, M.M.M. A Enfermagem e o humanismo. Lisboa: Lusociência, 1996.

CORREIA, F. A. A alteridade como critério fundamental e englobante da bioética. In: PESSINI, L.; BARCHIFONTAINE, C.P. (Org.). Fundamentos da Bioética. São Paulo: Paulus, 1996. Cap. 5.

MELEIS, A. I. Theoretical nursing: development and progress. 3.ed. Philadelphia: Lippincott, 1997.

MENDES, I.A.C. Enfoque humanístico à comunicação em Enfermagem. São Paulo: Sarvier, 1994.

MARCEL, G. Du refus à the l'invocation. Paris: Gallimard, 1940. In: GILSON, Etienne (Org.)

Existentialisme chretien: Gabriel Marcel. Paris: Libraire Plon, 1947. 